\title{
Diferentes linguagens e a música na Educação Infantil em uma turma de crianças pequenas
}

\author{
Distintos lenguajes y la música en la educación infantil en un grupo de \\ niños pequenos
}

Different languages and music in an early education group

\author{
Cinthia Peres Pacífico Gonçalves ${ }^{1}$ \\ Marta Cristina Cezar Pozzobon²
}

\begin{abstract}
Resumo
O presente artigo aborda as diferentes linguagens, incluindo a linguagem da música, em um cenário de Educação Infantil com uma turma de Berçário com faixa etária de 1 a 3 anos de idade, no Município de Pedro Osório/RS. A questão investigativa do trabalho é: de que modo as crianças do berçário se relacionam com a música em sala de aula? A metodologia desta pesquisa se deu pela filmagem de situações espontâneas das crianças em sala de aula e de situações com a intervenção da docente, com o uso de músicas infantis. Foram transcritos quatro vídeos, descrevendo as falas, os movimentos e gestos das crianças. Para as reflexões, considerou-se as discussões sobre linguagens e expressões artísticas, a partir da leitura de diversos autores, como Barbosa (2009), Amaral, Soares e Souza (2011), Bachelard (1996), Silva e Boufleur (2017), etc. As análises mostram que as crianças trazem vivências com o uso da música e usam o corpo para se expressarem. As situações espontâneas propiciadas às crianças em diferentes momentos de contato com a música, vão além de uma aula planejada com diversos recursos, mas são estes momentos que dão prazer, estimulam o gosto pela música, promovendo a aprendizagem e a interação.
\end{abstract}

Palavras-Chave: Educação Infantil; Linguagens; Música; Expressão Corporal.

\section{Resumen}

El presente artículo aborda los distintos lenguajes, incluyo el lenguaje musical, en un escenario de la Educación Infantil con un grupo de guardería con edades de 1 a 3 años, en la ciudad de Pedro Osório/RS. La cuestión investigativa del trabajo es: ¿De qué manera los niños de guardería se relacionan con la música en clase? La metodología de esta investigación se originó por videos de situaciones espontaneas de los niños en clase y de situaciones con la intervención de la docente, con el uso de músicas infantiles. Fueron transcritos cuatro videos, describiendo las hablas, los movimientos y expresiones de los niños. Para las reflexiones, se consideró las discusiones sobre lenguajes y expresiones artísticas, a partir de lectura de diversos autores, como Barbosa (2209), Amaral, Soares e Souza (2011), Bachelard (1996), Silva y Boufleur (2017), etc. Los estudios, muestran que los niños traen vivencias con el uso de la música y utilizan el cuerpo para expresarse. Las situaciones espontaneas propiciadas a los niños en distintos momentos de contacto con la música, van más allá de una clase planeada con distintos recursos, pero estos momentos son placenteros, estimulan el gusto por la música, promoviendo el aprendizaje y la interacción.

Palabras claves: Educación-Infantil; Lenguajes; Música; Expresión Corporal.

\footnotetext{
${ }^{1}$ Mestranda em Educação, Universidade Federal do Pampa/UNIPAMPA, Jaguarão, Rio Grande do Sul, Brasil, cinthiapacifico@hotmail.com.

${ }^{2}$ Doutora em Educação, Docente na Universidade Federal do Pampa/UNIPAMPA, Jaguarão, Rio Grande do Sul, Brasil, marta.pozzobon@hotmail.com.
} 


\begin{abstract}
This article addresses music language in a group of Early Childhood Education between the ages of 1 to 3, in Pedro Osório county, in Rio Grande Sul state. The study focused on how children relate to music in the classroom. The methodology used was not only filming the children in their spontaneous situation but also with the teacher's assistance, using infant songs. It was transcribed four videos: describing the talks, the movements and children's gestures. It was also considered Barbosa (2009), Amaral, Soares e Souza (2011), Bachelard (1996), Silva e Boufleur (2017) about languages and artistic expressions. The analysis shows that the children have music perception and use their bodies to express it. The different situations given to the children to show their spontaneity go beyond a planned class, but these moments give pleasure and stimulate music taste, promoting the leaning and interaction.
\end{abstract}

Keywords: Early Children Education; Language; Music; Body expression.

\title{
1. Introdução
}

A música se faz presente em todos os momentos de nossa vida, antes mesmo de nascermos, pois desde o ventre, o bebê é capaz de ouvir sons produzidos pela mãe (AMARAL; SOARES; SOUZA, 2011). Isso nos leva a problematizar as questões da linguagem musical e das outras linguagens presentes na Educação Infantil. A escolha do tema deu-se a partir de vivências de uma das autoras em sala de aula, como docente com as crianças pequenas, com uma turma de berçário na faixa etária de 1 a 3 anos de idade, no município de Pedro Osório/RS ${ }^{3}$. Nestas vivências, percebemos o interesse e o entusiasmo das crianças por atividades que envolvem a música, a dança, os diversos movimentos rítmicos e corporais, pois exploram o espaço da sala de aula e se expressam corporalmente, trazendo saberes já adquiridos em outros lugares, promovendo, assim, o contato e a aproximação entre alunos e professora.

As expressões e as diferentes linguagens corporais ou verbais são a todo o momento experienciadas no ambiente educacional por meio das práticas pedagógicas propostas na atuação docente. Nestas práticas, as crianças exploram os diferentes sons e variados tipos de vocabulários como elementos de desenvolvimento, tal como propõe o Parecer que revisa as Diretrizes Curriculares Nacionais para a Educação Infantil (DCNEI) ao se referirem que as:

Atividades que desenvolvam expressão motora e modos de perceber seu próprio corpo, assim como as que lhe possibilitem construir, criar e desenhar usando diferentes materiais e técnicas, ampliar a sensibilidade da criança à música, à dança, à linguagem teatral, abrem ricas possibilidades de vivências e desenvolvimento para as crianças (BRASIL, 2009, p. 16).

Com isso, pontuamos a importância de explorar as diferentes linguagens nas práticas pedagógicas com crianças pequenas, como a linguagem musical e corporal que são

\footnotetext{
${ }^{3}$ Município localiza-se na região Sul do Rio Grande do Sul, situa-se a 305 km de Porto Alegre/RS.
} 
diariamente consideradas no ambiente educacional, nas práticas pedagógicas da Educação Infantil. Diante de tais ideias nos propusemos a responder a seguinte questão de pesquisa: De que modo as crianças do berçário se relacionam com a música em sala de aula?

Acreditamos na relevância dessa pesquisa, com o intuito de dar mais visibilidade às práticas pedagógicas com a Educação Infantil, rompendo com a antigas práticas voltadas ao ensino das linguagens verbais e numéricas. Portanto, trazemos algumas discussões teóricas, os caminhos metodológicos, as vivências com o uso da Música e as considerações finais.

\section{Algumas discussões teóricas}

Consideramos que em diversas situações na sala de aula possam ser oportunizadas às crianças a exploração e o desenvolvimento das linguagens, principalmente a partir das expressões espontâneas, das interações com os colegas e professores e das intervenções pedagógicas. Como afirma Barbosa (2009, p. 84) “[...] o termo linguagem vem sendo utilizado socialmente para referir diferentes manifestações e expressões culturais, científicas e da vida cotidiana".

É importante destacar que "[...] nem todas as culturas valorizam as mesmas linguagens e oferecem para todos a oportunidade de desenvolvê-las" (BARBOSA, 2009, p. 84). Com isso, cabe a escola o papel de propiciar momentos prazerosos e significativos, para que as crianças se expressem, tanto verbal quanto corporalmente. Ou dito de outro modo, muitas vezes as crianças não são entendidas, nem respeitadas pelos adultos em suas manifestações e maneiras de se expressarem, até mesmo por questões culturais, como já citado, porém seus gestos e o uso do corpo dizem muito a respeito da criança e do meio em que vivem. Sendo assim, são nos momentos de prazer que a criança explora o meio em que está inserida de diversas formas, como por exemplo com o uso do corpo por meio da Música.

A Música está desde muito cedo presente na vida da criança. As experiências musicais podem se manifestar desde o princípio da vida do bebê, ainda no ventre da mãe. Desde bem cedo, dentro do útero da mãe, a criança já tem contato com diferentes sons:

\footnotetext{
Sons estes produzidos pela própria mãe como o som do coração, som da voz, entre outros, que mesmo sem perceber está estabelecendo um tipo de linguagem com seu filho. Quando a criança nasce se depara com um universo de sons produzidos pelos seres vivos e por objetos, pois, na maioria dos povos é muito comum que a mãe cante para seu bebê e assim passa acontecer os primeiros contatos com a música (AMARAL; SOARES; SOUZA, 2011, p. 29).
}

Como discutem os autores, a música pode propiciar uma forte conexão entre a mãe e o bebê antes do nascimento e posteriormente em seus primeiros anos de vida por meio de 
estímulos que podem ser desenvolvidos durante a infância. Este processo se dá continuamente, e pode ser experimentado em toda a trajetória de vida, e em vivências escolares posteriores, pois se relacionam intimamente com questões sociais e culturais. Neste sentido, o Referencial Curricular Nacional da Educação Infantil (RCNEI) volume 3 propõe que:

\begin{abstract}
Ouvir música, aprender uma canção, brincar de roda, realizar brinquedos rítmicos, jogos de mãos, etc., são atividades que despertam, estimulam e desenvolvem o gosto pela atividade musical, além de atenderem a necessidades de expressão que passam pela esfera afetiva, estética e cognitiva. Aprender música significa integrar experiências que envolvem a vivência, a percepção e a reflexão, encaminhando-as para níveis cada vez mais elaborados (BRASIL, 1998a, p. 48).
\end{abstract}

Com essas ideias, destacamos a importância da Música na Educação Infantil para o desenvolvimento integral da criança, trabalhando com o corpo e com noções de expressão através da arte, explorando múltiplas linguagens. Daremos atenção, principalmente à linguagem musical, uma vez que através da Música é possível desenvolver a integração social, o equilíbrio, o autoconhecimento, a imaginação, etc.

Conforme Silva e Boufleur (2017, p. 2), a Música pode ser concebida “[...] como forma de expressão e também para estabelecer regras, relações sociais, diversão, alegria e aprendizagem". A partir de sua forma simbólica, ocupa espaço em diversas culturas, transcende o tempo e aproxima sujeitos. Diferente das linguagens verbais, a linguagem musical comunica em qualquer território, a falantes de qualquer língua. Por essa quebra de barreiras espaciais e temporais, a Música em sua universalidade é uma maneira de expressão que nos aproxima enquanto humanidade.

A presença da música na vida das pessoas é incontestável, ela está presente em
diversas culturas e acompanha a história da humanidade presente nos diversos
continentes. A música se trata de uma forma de expressão artística, tanto no campo
popular, como no erudito. A linguagem musical faz-se presente nas diversas classes
sociais e também nas diferentes manifestações religiosas que se espalham por todo
território nacional (SILVA; BOUFLEUR, 2017, p. 1-2).

A partir dessas afirmações, se fizermos uma reflexão acerca da história da humanidade, veremos que a Música esteve sempre presente como forma de expressão cultural e registro de nossos sentimentos, de nossas inquietações culturais, sociais e políticas. Uma vez que, segundo Goleman (1995), a natureza humana é sempre regida pelos sentimentos e estes em grande parte são expressados através da arte.

Além disso, como ponto importante acerca da temática, destacamos a interdisciplinaridade proporcionada pela Música, produzindo práticas pedagógicas que podem contribuir com o desenvolvimento da criança nas diversas linguagens, como proposto por Correia (2003, p. 84-85): 
A música auxilia na aprendizagem de várias matérias. Ela é componente de questões, comportamentos, fatos e contextos de determinada fase da história. Os estudantes podem apreciar várias questões sociais e políticas, escutando canções, música clássica ou comédias musicais. O professor pode utilizar a música em vários segmentos do conhecimento, sempre de forma prazerosa, bem como: na expressão e comunicação, linguagem lógico-matemática, conhecimento científico, saúde e outras. Os currículos de ensino devem incentivar a interdisciplinaridade e suas várias possibilidades. [...] A utilização da música, bem como o uso de outros meios, pode incentivar a participação, a cooperação, socialização, e assim destruir as barreiras que atrasam a democratização curricular do ensino. [...] A prática interdisciplinar ainda é insípida em nossa educação.

Diante dessas discussões, trazemos na próxima seção os caminhos metodológicos, descrevendo os materiais e os procedimentos de pesquisa.

\section{Caminhos metodológicos}

A pesquisa é de cunho qualitativo, pois como propõe Godoy $(1995$, p. 21), esta abordagem “[...] enquanto exercício de pesquisa, não se apresenta como uma proposta rigidamente estruturada, ela permite que a imaginação e a criatividade levem os investigadores a propor trabalhos que explorem novos enfoques". Diante disso, salientamos a importância das pesquisas com crianças pequenas consideram estes sujeitos como "[...] atores sociais plenos, substituindo a visão da criança como um sujeito passivo para o entendimento de que ela é co-construtora de sua inserção social e cultural [...]" (RODRIGUES; BORGES; SILVA, 2014, p. 275).

Vale ressaltar que a prática com crianças envolve especificidades referentes aos direitos dos pequenos, previstos pelo RCNEI, dos quais destacamos:

[...] - o respeito à dignidade e aos direitos das crianças, consideradas nas suas diferenças individuais, sociais, econômicas, culturais, étnicas, religiosas etc.;

- o direito das crianças a brincar, como forma particular de expressão, pensamento, interação e comunicação infantil;

- o acesso das crianças aos bens socioculturais disponíveis, ampliando o desenvolvimento das capacidades relativas à expressão, à comunicação, à interação social, ao pensamento, à ética e à estética;

[...] A estes princípios cabe acrescentar que as crianças têm direito, antes de tudo, de viver experiências prazerosas nas instituições (BRASIL,1998b, p. 13-14).

A partir destes princípios, fundamentamos nossas práticas de maneira a garantir a autonomia das crianças e a liberdade de expressão através do corpo, da música, da brincadeira, ampliando os repertórios artístico-culturais dos pequenos, proporcionando espaço para a imaginação, a criação e intervenção artística pelo viés musical. Nesse sentido, a metodologia busca estar sempre em consonância com as noções de aprendizagem lúdica, com 
a finalidade de garantir experiências prazerosas na Educação Infantil como proposto nas DCNEI (BRASIL, 2010).

A partir dessas discussões, ponderamos que fazer pesquisa sobre crianças, é na verdade fazer pesquisa com crianças, no sentido de que é na interação com elas e oferecendolhes espaço para suas individualidades que se torna possível compreender os diversos fenômenos que atravessam nossas práticas em sala de aula. Foi atentando para essas discussões que este estudo foi desenvolvido a partir da observação do interesse das crianças por situações que envolvem a Música no cotidiano em sala de aula. Neste contexto, foram exploradas e analisadas as linguagens da Música e outras linguagens, como os movimentos e a expressão corporal. Em diversos momentos, de forma espontânea e a partir da intervenção docente, as crianças se expressavam por meio da Música. Estas situações foram observadas e registradas através de vídeos realizados pela docente.

Este estudo foi elaborado com 4 crianças, que são denominadas como criança A criança $B$, criança $C$ e criança $D$. Essas crianças são de uma turma do berçário, na faixa etária de 1 a 3 anos de idade, na qual uma das autoras atua como docente na cidade de Pedro Osório/RS.

Realizamos a filmagem de cinco situações, mas para este artigo trazemos apenas duas filmagens, as quais denominamos de episódio 1 e episódio 2. Assumimos juntamente com Pinheiro, Kakehash e Angelo (2005, p. 721) que “[...] o vídeo constitui um instrumento valioso para a coleta e geração de dados em pesquisas qualitativas".

A partir da filmagem de vídeos, os quais retratam momentos de expressão das crianças através da Música, realizamos as transcrições, que foram lidas e analisadas a partir dos referenciais. Os registros retratam as noções rítmicas e artísticas que as crianças possuem, demonstrando que assim como previsto em nossas discussões teóricas, a expressão por meio da Música é algo inerente ao ser humano e manifesta-se desde os primeiros anos de vida. Tais afirmações tornam-se visíveis nas análises propostas na próxima seção do artigo.

\section{As vivências com o uso da Música}

Nas discussões acerca das linguagens, a Música é compreendida como discurso, como forma simbólica de expressão, em que as manifestações das crianças ao utilizarem a linguagem corporal e musical retratam as situações vivenciadas. Através da música as crianças demonstram que a partir dos sons já podem manifestar suas visões de mundo, pois aprendem e ensinam sobre coletividade e divertimento. Tais situações serão demonstradas nas transcrições abaixo: 


\section{Episódio 1}

A criança A está cantando e se movimentando suavemente em cima de um tapete azul, com um guarda-chuva em uma das mãos e balançando um brinquedo luminoso na outra.

Se escuta a voz da criança A e da docente cantando a seguinte música:

Criança A: Tá chovendo.

Criança A e docente: Tá chovendo.

Criança A: Sem paia.

Acriança A para de cantar e esfrega o nariz com a mão que está com o brinquedo luminoso.

Docente: que fazer?

A criança A, com voz de outras crianças ao fundo: o que fazê?? Abe o guada-chuva, abe o guadachuva é pa se estocode.

A criança A agora está segurando o guarda-chuva com a mesma mão do brinquedo luminoso e está girando o guarda-chuva olhando para o gancho onde se segura o mesmo e para a docente alternadamente.

Leves sons de risos no fundo.

Criança A: é isso?

Docente: Pra se esconder. Muito beeeem!

Criança A: Eeee.

Criança A: Muito bem!

Aparece a criança B no vídeo, em pé ao lado do tapete azul, batendo palmas para cima.

Docente: Muito bem!

Quadro 1 - Episódio 1

Fonte: filmagem em 09 de outubro de 2018.

A partir do episódio acima, observamos diversas atitudes espontâneas envolvendo noções de expressão corporal, ritmo, expressão de sentimentos, etc. Essas vivências mostram que as crianças usam o seu corpo como forma de expressão e quando estimuladas são capazes de cantar canções que expressam atitudes cotidianas, bem como relacioná-las a coreografias utilizando-se de objetos.

Pontuamos que apesar da expectativa de reproduzirem a letra original da canção, a criança A mostra uma tentativa de seguir a letra original, e, ainda, percebe, olhando para rua através da janela, que chove sem parar e que não poderíamos brincar na rua. Através disso, consideramos a respeito da formação cultural e artística das crianças passa também por suas vivências cotidianas, e este processo é atravessado pela fala dos pais dos alunos, dos professores e das influências de entretenimento que as crianças têm, como os desenhos animados, por exemplo. Com base nessas questões, observamos que todos os estímulos cotidianos corroboram para a construção das performances artísticas e criativas das crianças, seja através da criação de novas letras para as canções, ou até mesmo através do uso de objetos ou coreografias

Ainda, destacamos que a partir da intervenção da professora, a criança demonstra a partir da música e do manuseio dos objetos que, a alternativa quando o clima é chuvoso, é 
abrir o guarda-chuva. Para tanto, canta, manuseia o guarda-chuva e tenta chamar a atenção através do olhar para o objeto, a fim de chamar a atenção da professora e demonstrar que é fácil solucionar o problema da chuva. O uso dos objetos somados à expressão corporal e musical dialoga com as ideias de Barbosa (2009, p. 56), as quais preveem que: "As linguagens ocorrem no encontro de um corpo que simultaneamente age, observa, interpreta e pensa num mundo imerso em linguagens, com pessoas que vivem em linguagens, em um mundo social organizado e significado por elas".

Os usos de múltiplas linguagens presentes nas manifestações humanas demonstram de maneira aprofundada as ideias e percepções que os sujeitos têm sobre o mundo. No caso analisado, a linguagem corporal evidencia ainda mais a mensagem trazida pela letra da música, dessa maneira, o corpo da criança e a forma como carrega os objetos chamam a atenção para ênfase que ela tenta dar ao uso do guarda-chuva.

\section{Episódio 2}

A criança $E$ se encontra sentada no chão em cima de um tapete tocando com uma baqueta em um tambor feito de lata. Ao redor do tapete tem uma criança que passa no fundo do vídeo carregando uma almofada. A criança $E$ tenta se levantar tocando o instrumento e acaba sentando novamente, pegando o instrumento na mão. Ao fundo ouvimos as vozes de outras crianças falando.

Aparece outra criança que é a criança A caminhando ao fundo do vídeo também tocando um tambor de lata, a menina senta no tapete juntamente com a criança $\mathrm{E}$, e tocam juntos.

A criança E começa a cantar com balbucios.

Criança E: A le a le a, a lelea, a le a, o iu a leia oa aaaaa (balbucios).

A criança A toca um pouco o tambor e vira o mesmo, assim ela faz repetidamente. Ela levanta o tambor e coloca nas costas.

CriançaE: ão, fu u tem.

Docente: Um trem. Vamos cantar a música do trem?

Ao fundo uma criança que não está aparecendo no vídeo responde:

Vamooooo.

Docente: Então vamos cantar.

A criança E volta a tocar seu instrumento e a criança A manuseia um tecido amarelo.

Quadro 2 - Episódio 2

Fonte: filmagem em 22 de novembro de 2018.

A partir deste registro, é possível analisarmos acerca de como o ritmo e a linguagem musical podem auxiliar no processo de aquisição da linguagem verbal, uma vez que muitas crianças na Educação Infantil ainda não dominam esta linguagem e utilizam-se da Música como ferramenta de expressão e comunicação. Além disso, foi possível perceber que as crianças utilizam alguns objetos como instrumentos musicais e até mesmo alguns materiais concretos, associando-os a Música que estavam cantando. 
A sensibilização musical das crianças e a intervenção da docente estimulam e encorajam as mesmas a arriscarem o uso de diversas linguagens. A criança que ainda está aprendendo a falar, através da Música, consegue se comunicar e manifestar seu interesse em cantar e tocar alguma canção em específico, demonstrando que as utilizações de outras linguagens afloram também o senso crítico das crianças que fazem juízo de valor e apontam preferências musicais. Essas ideias se aproximam das discussões de Maffioletti (2015, p. 120):

As crianças, em geral, e os bebês, em particular, mostram-se muito receptivos às interações com a música, confirmando a ideia de que a música pode criar um espaço intersubjetivo onde as relações de contato, de proximidade e de interação são potencializadas. Os componentes musicais da fala, como as continuidades e descontinuidades, as ênfases, os prolongamentos vogais, as inflexões em movimento ascendente e descendente, todos esses recursos participam do contexto das interações que permitem a compreensão da mensagem falada. Perceber essas nuanças sonoras é essencial para organizar e reorganizar a comunicação entre as pessoas.

Além disso, é importante ressaltar que é através do estreitamento dos laços e da sensibilidade da docente que se torna possível que a criança potencialize as expressões sonoras, as quais já vêm dotadas do significado daquilo que deseja comunicar. Sendo assim, é possível analisarmos este episódio como uma manifestação musical que vem ao encontro do processo de aquisição da linguagem verbal ainda em andamento.

\section{Considerações finais}

Com base nas vivências em sala de aula e nos referenciais, podemos destacar que as situações espontâneas envolvendo a Música, ultrapassam a ideia de uma aula planejada com diversos recursos, pois são estes momentos que dão prazer, estimulam o gosto musical, promovem aprendizagens e a interação entre as crianças.

A partir dessas considerações e das vivências com a utilização de diversas linguagens em sala de aula, é possível depreender diversas conclusões sobre a importância da arte na formação cultural e social das crianças. Percebemos que através da utilização de propostas lúdicas em sala de aula, estaremos contribuindo com outros processos de aprendizagem das crianças, instigando a memorização, a criticidade, a aquisição da linguagem verbal, entre outras.

Além disso, percebemos que as crianças são extremamente receptivas à arte, principalmente na linguagem da Música. A utilização desta linguagem em sala de aula estimula a liberdade de expressão, bem como garante o prazer e a brincadeira. Essas ideias dialogam com os direitos das crianças previsto nas DCNEI (BRASIL, 2010). Através da 
construção de um ambiente saudável e de brincadeiras, em que a Música se faz presente cotidianamente, garante-se não só o aprimoramento das competências cognitivas para auxiliar na aprendizagem formal, mas também a criação de um vínculo entre as crianças e as crianças e a professora. Além disso, a inserção da criança à linguagem musical gera um processo de identificação cultural, fazendo com que se perceba em uma comunidade e comece o processo de formação de sua identidade social. Tais discussões se aproximam das ideias de Maffioletti (2015, p. 121):

\begin{abstract}
A inserção das crianças na cultura musical ocorre a partir do engajamento em atividades musicais, com motivos e estilos compartilhados pela comunidade. Gratier e Apter-Danon (2009) defendem que, para além do engajamento, o sentimento de pertencimento a uma cultura requer a possibilidade de invenção de novas formas de expressão e a abertura de espaços de intimidade comunicativa fundamentados no "estar juntos no tempo". Esse "estar juntos" é um espaço intersubjetivo facilmente criado nas relações que envolvem a música.
\end{abstract}

Com base nessas afirmações é possível concluir que a prática musical e as múltiplas linguagens no contexto da Educação Infantil é um processo fundamental na formação das crianças e no seu desenvolvimento integral. Nesse sentido, ressaltamos a importância de um aprofundamento destes estudos, para que possamos adotar práticas capazes de aperfeiçoar o fazer docente na Educação Infantil, colaborando, assim, com a aprendizagem e o desenvolvimento de nossas crianças.

\title{
Referências
}

AMARAL, M. L. F.; SOARES, L. C. S.; SOUZA, E. V. Construção de Instrumentos de Percussão: uma experiência na educação infantil. In: SEMINÁRIO BRASILEIRO DE EDUCAÇÃO MUSICAL INFANTIL, 2., 2011, Salvador. Anais... Salvador, 2011.

BACHELARD, Gaston. A formação do espírito científico: contribuição para uma psicanálise do conhecimento. Tradução de Esteia dos Santos Abreu. Rio de Janeiro: Contraponto, 1996.

BARBOSA, M. C. S. Práticas cotidianas na Educação Infantil: base para a reflexão sobre as orientações curriculares. Brasília: MEC/SEB/DCOCEB/CGEI, 2009.

BRASIL. Referencial curricular nacional para a educação infantil. Brasília: MEC/SEF, 1998a. v. 3. 1998b. v. 1.

Referencial curricular nacional para a educação infantil. Brasília: MEC/SEF,

. Parecer CNE/CEB 20/2009. Revisão das Diretrizes Curriculares Nacionais para a Educação Infantil. Diário Oficial da União, Poder Executivo, Brasília, DF, 9 dez. 2009. Disponível em: http://portal.mec.gov.br/dmdocuments/pceb020_09.pdf. Acesso em: 20 nov. 2018. 
Diretrizes curriculares nacionais para a educação infantil. Brasília: MEC/SEB, 2010.

CORREIA, M. A. Música na Educação: uma possibilidade pedagógica. Revista Luminária, União da Vitória, n. 6, p. 83-87, 2003.

GODOY, A. S. Pesquisa Qualitativa Tipos Fundamentais. Revista de Administração de Empresas, São Paulo, v. 35, n. 3, p. 20-29, jun. 1995. ISSN 0034-7590. Disponível em: http://www.scielo.br/scielo.php?script=sci_arttext\&pid=S0034-75901995000300004. Acesso em: 20 nov. 2018.

GOLEMAN, D. Inteligência Emocional. Rio de Janeiro: Objetiva. 1995.

MAFFIOLETTI, L. A. A música e as primeiras aprendizagens da criança. In: FLORES, M. L. R.; ALBUQUERQUE, S. S. (Orgs.). Implementação do Proinfância no Rio Grande do Sul: perspectivas políticas e pedagógicas. Porto Alegre: EDIPUCRS, 2015.

PINHEIRO, E. M.; KAKEHASH, T. Y.; ANGELO, M. O uso de filmagem em pesquisas qualitativas. Rev. Latino-Am. Enfermagem, Ribeirão Preto, v. 13, n. 5, p. 717-722, out. 2005. ISSN 1518-8345. Disponível em:

http://www.scielo.br/scielo.php?script=sci_arttext\&pid=S0104-

$11692005000500016 \& \operatorname{lng}=$ en\&nrm=iso. Acesso em: 10 dez. 2018.

RODRIGUES, S. A.; BORGES, T. F. P.; SILVA, A. S. "Com olhos de criança": a metodologia de pesquisa com crianças pequenas no cenário brasileiro. Nuances: estudos sobre Educação, Presidente Prudente, v. 25, n. 2, p. 270-290, maio/ago. 2014. ISSN 22360441. Disponível em: http://revista.fct.unesp.br/index.php/Nuances/article/view/3188/2698. Acesso em: 20 nov. 2018.

SILVA, C. L.; BOUFLEUR, E. M. Musicalização na educação infantil: uma reflexão sobre as contribuições da música no desenvolvimento da criança. Revista Magsul de Educação da Fronteira, Ponta Porã, v. 2, n. 1, p. 48-70, mar. 2017. ISSN 2526-4796. Disponível em: http://bibmagsul.kinghost.net/revista2016/index.php/educfronteira/article/viewFile/281/257. Acesso em: 20 nov. 2018. 